\title{
Proposta de um Painel de Informações Sintéticas sobre as Uni- versidades: Aplicação do "Raio-X" na Universidade Federal de Santa Catarina
}

Proposal of a Panel with Synthetic Information about Universities:

Application of the "X-Ray" in the Federal University of Santa Catarina

\section{Orion Augusto Platt Neto}

Doutor em Engenharia de Produção pela Universidade Federal de Santa Catarina

Professor da Universidade Federal de Santa Catarina

Endereço: Universidade Federal de Santa Catarina (UFSC). Centro Sócio-Econômico (CSE). Departamento de Ciên-

cias Contábeis $(\mathrm{CCN})$. Campus Universitário do Bairro Trindade - Florianópolis

CEP: 88040-970 - Florianópolis/ Santa Catarina - Brasil

E-mail: orionplatt@cse.ufsc.br

Telefone: (48) 3234-9579

\section{Flávio da Cruz}

Mestre em Administração pela Universidade Federal de Santa Catarina

Professor da Universidade Federal de Santa Catarina

Endereço: Universidade Federal de Santa Catarina (UFSC). Centro Sócio-Econômico (CSE). Departamento de Ciências Contábeis (CCN). Campus Universitário do Bairro Trindade - Florianópolis

CEP: 88040-970 - Florianópolis/ Santa Catarina - Brasil

E-mail: flacruz9@ativanet.com.br.

Telefone: (48) 3234-3407

Artigo recebido em novembro de 2008. Passou por uma avaliação double blind review em agosto de 2009. Aceito em novembro de 2009 pela Editora Científica Sandra Rolim Ensslin. Artigo apresentado no VIII Colóquio Internacional sobre Gestão Universitária na América do Sul, 2008, Assunção, Paraguai, 2008. 


\title{
Resumo
}

As universidades são organizações peculiares, cujas informações operacionais e orçamentárias assumem complexidade significativa. O objetivo deste artigo é apresentar a proposta de um painel de informações institucionais básicas de universidades brasileiras, a partir de uma concepção sintética e ilustrada. A partir da identificação de informações divulgadas, foram selecionadas algumas consideradas básicas e relevantes para o público em geral, diante da restrição de espaço própria da abordagem sintética de painel. A partir disto, foi proposto um painel intitulado "Raio-X", cuja aplicação pode ser realizada para todas as Instituições Federais de Ensino Superior, face à demanda de publicações mínimas comuns.

Palavras-Chave: Universidades, Painel de Informações, Transparência Governamental.

\begin{abstract}
Universities are peculiar organizations whose operational and budgetary information assume significant complexity. The objective of this article is to present the proposal of a panel with basic institutional information about Brazilian universities, with a synthetic and illustrated conception. With the identification of available information, those considered basic and relevant, were selected according to the space restriction for the synthetic approach of a panel. Then, it was proposed a panel entitled "X-Ray", which application can be carried through for any Federal Institutions of Superior Education of the Brazilian Federal Government, taking in to consideration the common and minimum reports demanded.
\end{abstract}

Key words: University, Information Panel, Governmental Transparency.

\section{Introdução}

As universidades públicas são entidades que compõem a estrutura da administração pública brasileira. Comumente são constituídas nas formas de autarquias ou fundações, componentes da administração indireta, e são dependentes de recursos públicos. Em função disto, são obrigadas, conforme os artigos $37 \mathrm{e}$ 70 da Constituição Federal, a prestar contas do uso de seus recursos e respeitar o princípio da publicidade, entre outros princípios da administração pública.

No Brasil, o ensino superior tem sido oferecido não só por universidades públicas. Observa-se, entre as universidades privadas, a existência de instituições vinculadas a irmandades religiosas, bem como as de fins filantrópicos ou não, que atuam devidamente autorizadas pelo Ministério da Educação.

As peculiaridades das universidades fazem com que as informações operacionais e orçamentárias assumam complexidade significativa. Ao mesmo tempo, existe a necessidade de transparência quanto às informações institucionais e ao desempenho. Tal demanda contrasta com os relatórios extensos publicados pelas universidades, pouco práticos para consultas de usuários não especializados, apesar de oficialmente exigidos pelos órgãos de controle.

Neste sentido, este artigo tem o objetivo de apresentar a proposta de um painel de informações institucionais básicas de universidades brasileiras, a partir de uma concepção sintética e ilustrada. Não há a pretensão de propor uma versão 
definitiva, face à abordagem construtivista e adaptável em termos de conteúdo, customizável aos interesses dos usuários.

É notória a necessidade de transparência das contas das universidades públicas, bem como de outras informações institucionais de interesse geral. Este tema, de relevante importância social, vem recebendo maior destaque em leis recentes, como no caso da Lei de Responsabilidade Fiscal (LRF). A LRF fundamenta-se em princípios como o planejamento, a transparência e a participação popular. A participação popular depende fortemente da transparência das ações governamentais e de outras informações, pois sem informações as decisões são prejudicadas.

Foi realizada a revisão de literatura e a análise documental de relatórios diversos da Instituição utilizada no estudo de caso, a Universidade Federal de Santa Catarina (UFSC). A partir da identificação de informações divulgadas ao público, foram selecionadas algumas consideradas básicas e relevantes para o público em geral, diante da restrição de espaço própria da abordagem sintética de painel.

A partir disto, foi proposto um painel intitulado "Raio-X" da UFSC, cuja aplicação pode ser estendida imediatamente para todas as Instituições Federais de Ensino Superior (IFES), do Governo Federal brasileiro, face à demanda de publicações mínimas comuns.

Mais do que garantir o atendimento das normas legais, as iniciativas de transparência nas universidades constituem uma política de gestão responsável que favorece o exercício da cidadania pela população. Potencialmente, a atitude poderá servir de estímulo aos estudantes, professores e demais servidores, contribuindo para o hábito de solicitar esclarecimentos junto às entidades governamentais, como parte do processo de formação para o exercício da cidadania.

\section{Revisão da Literatura}

\subsection{Transparência das contas públicas}

A publicidade na administração pública brasileira está estabelecida como princípio no artigo 37 da Constituição Federal de 1988 e detalhada em seu parágrafo primeiro, conforme transcrito a seguir:

$\S 1^{\circ}$ A publicidade dos atos, programas, obras, serviços e campanhas dos órgãos públicos deverá ter caráter educativo, informativo ou de orientação social, dela não podendo constar nomes, símbolos ou imagens que caracterizem promoção pessoal de autoridades ou servidores públicos.

De maneira complementar, o ordenamento jurídico prevê várias normas que disciplinam a prestação de contas dos gestores públicos ao poder público e 
à comunidade em geral.

No ano de 2000, com a publicação da Lei Complementar n⿳0 101 , conhecida como Lei de Responsabilidade Fiscal (LRF), a exigência de transparência recebeu um novo reforço no âmbito estatal brasileiro. Cruz et al (2001, p. 183) apresentam o entendimento dado à transparência na LRF da seguinte forma:

\begin{abstract}
A transparência na gestão fiscal é tratada na Lei como um princípio de gestão, que tem por finalidade, entre outros aspectos, franquear ao público acesso a informações relativas às atividades financeiras do Estado e deflagrar, de forma clara e previamente estabelecida, os procedimentos necessários à divulgação dessas informações.
\end{abstract}

Deste modo, a transparência, como princípio da gestão fiscal responsável, pressupõe a publicidade e a compreensibilidade das informações.

São considerados instrumentos de transparência da gestão fiscal (art. 48) os "planos, orçamentos e lei de diretrizes orçamentárias; as prestações de contas e o respectivo parecer prévio; o Relatório Resumido da Execução Orçamentária e o Relatório de Gestão Fiscal; e as versões simplificadas desses documentos".

Quanto à forma de divulgação, a LRF estabelece que deve ser dada ampla divulgação a tais instrumentos de transparência, inclusive em meios eletrônicos de acesso público, como a Internet. Conforme dados do IBGE (2007), ao final de 2006, existiam aproximadamente 30 milhões de usuários da Internet, para uma população de aproximadamente 188 milhões, o que resulta em $16 \%$ da população com acesso à rede mundial de computadores.

A Internet, como meio para o fortalecimento das relações entre o governo e o cidadão, tem sido alvo de muitos estudos atuais. No entanto, apenas uma parcela reduzida da população brasileira é usuária da Internet.

A primeira iniciativa legal no sentido de incorporar a obrigatoriedade da divulgação de informações das contas públicas na Internet surgiu por meio da Lei ${ }^{\circ}$ 9.755/98, que criou a página da Internet (homepage) Contas Públicas (www.contaspublicas.gov.br). Por meio de tal página, todas as entidades gestoras de recursos públicos são obrigadas a disponibilizar determinadas informações orçamentárias e financeiras mensalmente.

Destaca-se também a criação em 1994 do Portal da Transparência (<www. portaltransparencia.gov.br>), da Controladoria-Geral da União (CGU, 2006), que traz informações sobre a aplicação de recursos do governo federal, abrangendo transferências e aplicações diretas.

Ainda por parte de CGU, foi editada a Portaria $\mathrm{n}^{\circ} 262$, de 2005, que estabelece que os órgãos e entidades do Poder Executivo Federal sujeitos a tomada e prestação de contas anuais manterão, em seus sítios eletrônicos na Internet, página com o título "Processos de Contas Anuais", na qual se dará a divulgação dos relatórios e dos certificados de auditoria, com pareceres do órgão de controle 
interno, e dos pronunciamentos dos Ministros de Estado supervisores das áreas ou das autoridades de nível hierárquico equivalente, contidos nos processos de contas anuais (CGU, 2005).

Não há um impedimento ou proibição para que os entes estatais em geral, ou as instituições federais de ensino em particular, sejam criativos e busquem, de forma constante, aproximar as modalidades de veiculação de dados às necessidades de simplificação manifestadas ou percebidas junto aos usuários.

\subsection{As contas das universidades públicas e seus usuários}

Observou-se que nos registros da homepage Contas Públicas (2008), regulada pelo TCU, constam as universidade e faculdades financiadas com recursos federais. No entanto, a consulta aos links oferecidos revelou que nenhuma das instituições possui informações de contas públicas cadastradas.

O motivo para isto está embasado no Ofício $n^{\circ} 301 / 2000-\mathrm{MEC} / \mathrm{SPO} /$ GAB, da Subsecretaria de Planejamento e Orçamento, da Secretaria Executiva do Ministério da Educação, em 25 de maio de 2000. Referido ofício comunica que em reunião realizada com a Secretaria de Controle Externo do TCU, concluiu-se que não cabe a inserção dos dados e informações na homepage contas públicas pelos órgãos descentralizados, à exceção do FNDE (Fundo Nacional de Desenvolvimento da Educação).

No Portal da Transparência, da Controladoria Geral da União (CGU, 2008), observou-se que constam todas as IFES nas possibilidades de buscas de aplicações de recursos associadas ao Ministério da Educação, com as possibilidades de obtenção de informações mencionadas na seção anterior.

O entendimento assumido nesta pesquisa para o termo "contas públicas" é: o conjunto de dados e informações de natureza econômico-financeira das entidades públicas, produzidas pelos órgãos de contabilidade, planejamento e orçamento. Tais informações podem associar dados monetários com não monetários, de natureza financeira, orçamentária e operacional, das atividades organizacionais.

O quadro a seguir demonstra os principais usuários externos das informações das contas públicas das universidades e traz uma síntese dos interesses presumíveis dos mesmos. Alguns destes são também usuários internos, quando utilizam as informações para realização de seus trabalhos junto à instituição.

Destaca-se que esta lista não é exaustiva em termos de usuários ou de interesses. Existem ainda os usuários estatais, tais como o Tribunal de Contas da União (TCU), a Controladoria-Geral da União (CGU) e o Ministério Público Federal (MPF), que não foram incluídos na lista anterior em função de disporem de outros recursos computacionais para acesso e verificação das contas das instituições federais de ensino superior. 


\section{Quadro 1: Usuários externos das contas públicas das universidades e síntese de seus interesses}

\begin{tabular}{|l|l|}
\hline Usuários & Síntese dos Interesses Presumíveis \\
\hline Alunos & $\begin{array}{l}\text { Exercer a participação política e o controle social, auxiliando a escolha e a atuação de reitores, } \\
\text { diretores de centros, chefes de departamentos e outros representantes que atendam aos seus } \\
\text { anseios. }\end{array}$ \\
\hline Servidores & $\begin{array}{l}\text { Exercer a participação política e o controle social, auxiliando a escolha e a atuação de reitores, } \\
\text { diretores de centros, chefes de departamentos e outros representantes, que atendam aos seus } \\
\text { anseios. Seus interesses abrangem assuntos de classe relacionados a condições de trabalhos, } \\
\text { que dependam de recursos financeiros. }\end{array}$ \\
\hline Fornecedores & $\begin{array}{l}\text { Decisão de venda à instituição, através do conhecimento da demanda, da capacidade e da } \\
\text { execução de pagamentos. }\end{array}$ \\
\hline $\begin{array}{l}\text { Sindicatos dos } \\
\text { Servidores }\end{array}$ & $\begin{array}{l}\text { Negociar remunerações, condições gerais de trabalho e benefícios de servidores docentes e } \\
\text { técnico-administrativos. }\end{array}$ \\
\hline $\begin{array}{l}\text { ONGs, } \\
\text { Associações, } \\
\text { OCIPs,etc. }\end{array}$ & Acompanhar e fiscalizar a ação governamental, de acordo com suas finalidades. \\
\hline Pesquisadores & Desenvolver estudos acadêmico-científicos sobre as universidades, sua gestão e finanças. \\
\hline $\begin{array}{l}\text { Meios de } \\
\text { Comunicação }\end{array}$ & Divulgação de notícias e matérias investigativas. \\
\hline
\end{tabular}

Fonte: Elaborado pelos autores.

\section{Procedimentos Metodológicos}

Quanto a sua natureza, a pesquisa que deu origem a este artigo é classificada como aplicada. Quanto à forma de abordagem do problema, a pesquisa é classificada como qualitativa. Quanto aos objetivos, a pesquisa é exploratória, pois visa favorecer a compreensão dos problemas enfocados, visando contribuir com a assimetria informacional. A visão de conhecimento assumida é construtivista e o paradigma científico é o fenomenológico.

Foi realizada uma revisão de literatura para formação da base conceitual e legal para abordagem do problema, que abrangeu a publicidade e a transparência governamental, conforme e literatura técnico-científica relacionada, com enfoque sobre a divulgação de informações contábeis e operacionais das universidades públicas brasileiras.

Foi realizada a análise documental de relatórios diversos da Instituição utilizada no estudo de caso. A partir da identificação de informações divulgadas ao público, foram selecionadas algumas consideradas básicas e relevantes para o público em geral, diante da restrição de espaço própria da abordagem sintética de painel. Para isto, valeu-se dos conhecimentos especializados dos autores deste artigo. Este fato caracteriza uma limitação inerente das pesquisas com abordagem qualitativa.

O âmbito da pesquisa é restrito às instituições dedicadas ao ensino superior componentes da administração indireta na esfera federal brasileira, ou seja, as universidades federais. Tendo em vista a abordagem qualitativa e aos instru- 
mentos utilizados, não há a pretensão de propor uma versão definitiva de painel de informações. Por este motivo, a proposta é adaptável em termos de conteúdo, customizável aos interesses dos usuários.

\section{Resultados}

Nesta seção é apresentada a proposta de um painel intitulado "Raio-X da Universidade", com dados reais da aplicação do modelo na Universidade Federal de Santa Catarina (UFSC). Inicialmente, são feitas considerações sobre os princípios que nortearam a proposta. Em seguida, são apresentadas as características do painel proposto, com o embasamento metodológico dos procedimentos e dos significados das informações disponibilizadas.

Por fim, são apresentadas as limitações inerentes ao modelo/exemplo proposto, com a indicação de possibilidade de ampliação e/ou customização das informações, conforme vertentes inerentes às universidades e aos interesses potenciais dos usuários interessados.

\subsection{Breve apresentação da Instituição estudada e das informações existentes}

A Universidade Federal de Santa Catarina (UFSC) é uma Instituição Federal de Ensino Superior (IFES) vinculada ao Ministério da Educação (MEC) do Governo Federal do Brasil. Constituída na forma de autarquia (entidade da administração indireta), é dependente de recursos públicos para o financiamento de suas atividades e realização de despesas.

A UFSC foi fundada no ano de 1960 por meio da Lei $n^{\circ} 3.849 / 60$ e sua Reitoria está sediada no Município de Florianópolis, Estado de Santa Catarina. Trata-se de uma Universidade participante da rede de IFES, em situação semelhante às demais mantidas pelo Governo Federal.

Segue a transcrição da missão da Instituição, aprovada pela Assembléia Estatuinte em 04 de junho de 1993 (UFSC, 2008):

A Universidade Federal de Santa Catarina tem por finalidade "produzir, sistematizar e socializar o saber filosófico, científico, artístico e tecnológico, ampliando e aprofundando a formação do ser humano para o exercício profissional, a reflexão crítica, solidariedade nacional e internacional, na perspectiva da construção de uma sociedade justa e democrática e na defesa da qualidade de vida".

Até o ano de 2007, a UFSC possuía 65 cursos de graduação e 52 programas de pós-graduação. Outras informações institucionais relevantes são apresentadas no painel proposto, constante na seção a seguir.

As IFES divulgam periodicamente uma série de informações institucio- 
nais relativas a aspectos operacionais e orçamentários. As principais fontes são: o Relatório de Gestão e o processo de Prestação de Contas, ambos anuais. Porém, existem muitos outros relatórios, páginas na Internet e publicações que estão disponíveis aos interessados.

A seguir, são apresentados alguns setores da UFSC que divulgam informações que podem subsidiar a elaboração do painel proposto, bem como apoiar outras pesquisas.

\section{a) Departamento de Contabilidade e Finanças (DCF)}

O DCF tem a missão de "tornar o processo financeiro/contábil mais ágil e eficiente, otimizando a integração do DCF com seus usuários", sendo composto por uma coordenadoria e três divisões. Entre as competências da Divisão de Administração, estabelecida em seu regimento, estão "Manter a Home Page do Departamento atualizada e em permanente sincronia com os seus usuários" e "Prestar informações a fornecedores, no que diz respeito aos pagamentos efetuados pela Instituição".

Em sua página na Internet (http://www.reitoria.ufsc.br/dcf/), são disponibilizadas algumas informações sobre as contas públicas. Quanto aos demonstrativos contábeis, estão publicados na Internet os quatro balanços da UFSC: orçamentário, financeiro, patrimonial e variações patrimoniais.

A página do DCF fornece também informações sobre pagamentos a fornecedores. Para os fornecedores, é possível cadastrar seu e-mail para receber notificações de pagamentos da UFSC. Qualquer pessoa pode consultar os pagamentos feitos às empresas com base no número do CNPJ da mesma.

\section{b) Departamento de Gestão Orçamentária (DGO)}

O DGO é encarregado do orçamento da UFSC, abrangendo a elaboração, proposta, acompanhamento e avaliação do orçamento, entre outras atividades relacionadas. A homepage do DGO fornece as seguintes informações a respeito do orçamento da UFSC:

a) Demonstrativo do orçamento, que apresenta dados relativos às despesas de: pessoal e encargos sociais; Outros benefícios sociais; Outros custeios e capital - tesouro; e Outros custeios e capital - diretamente arrecadados;

b) Proposta orçamentária, com identificação do programa de trabalho, especificação da despesa, natureza, código da fonte e valor total para o ano;

d) Execução Orçamentária, indicando: recursos do tesouro - outros custeios e capital; recursos do tesouro - pessoal; recursos de convênios; recursos próprios - fontes 0250 ; recursos próprios - fontes 280; e recursos próprios - fontes 0281 ; e 
e) Distribuição por unidade orçamentária, com tabelas de despesas referentes a: centros de ensino; colégios; pró-reitorias; entre outras unidades administrativas.

Destaca-se, ainda, que podem ser obtidas informações sobre a execução orçamentária da UFSC também no Portal da Transparência, da ControladoriaGeral da União (CGU).

\section{c) Departamento de Integração e Estatística (DIE)}

O DIE é o órgão responsável pelo planejamento da administração central, anteriormente conhecido como Programa de Planejamento Institucional (PIP). A homepage do DIE (http://www.die.ufsc.br) contém, no que tange às contas públicas:

a) o Relatório de Gestão da UFSC, referente aos anos de 2000 a 2007;

$\mathrm{e}$

b) e o Boletim de Dados da UFSC, referente aos anos de 2000 a 2006.

Constam ainda na página do DIE: o Plano de Desenvolvimento Institucional; o Plano Institucional; e o relatório UFSC em Números (1996 a 2007).

Nos Relatórios de Gestão da UFSC encontram-se informações exigidas pelo Tribunal de Contas da União por meio da Decisão n 408/2002 e Decisão Normativa TCU n ${ }^{\circ}$ 62, além de normas emitidas pelo Grupo de Contato (2006). Tal seção do relatório abrange indicadores, como o de custo por aluno, e a avaliação do cumprimento dos objetivos e metas constante no Plano Plurianual.

\section{d) Auditoria Interna (AUDIN)}

A unidade de Auditoria Interna (AUDIN) da UFSC tem as seguintes finalidades básicas: "fortalecer a gestão; racionalizar as ações de controle e prestar apoio aos órgãos do Sistema de Controle Interno do Poder Executivo Federal". Entre suas atividades está: "Examinar e emitir parecer sobre a prestação de contas anual da Universidade e tomadas de contas especiais" (AUDIN, 2008).

$\mathrm{Na}$ homepage da AUDIN (http://www.audin.ufsc.br) são divulgados os Relatórios de Atividades de 1996 a 2007. Nestes, a AUDIN evidencia as ressalvas apontadas com as devidas recomendações constantes dos Relatórios de Auditoria da Controladoria-Geral da União (CGU) e as determinações do Tribunal de Contas da União (TCU). Associadas às ressalvas, recomendações e determinações, são também divulgadas as ações adotadas pelas diversas unidades administrativas para o saneamento das impropriedades indicadas, além de registrar as pendências ainda existentes.

\subsection{A proposta do painel Raio-X e seus princípios norteadores}


A idéia de apresentar informações extensas e complexas de forma simplificada e amigável pode ser considerada um princípio para uma comunicação bem sucedida, especialmente se os usuários das informações compõe um público variado e não especializado. A responsabilidade pela compreensão das informações está tanto com o emissor quanto com o receptor. Deste modo, todos os agentes precisam apresentar disposição e algum interesse, tanto de compreender quanto de se fazer compreender.

A analogia do painel com uma lâmina de radiografia (a partir de raios x) é intuitiva, pois se trará de um recurso que permite ver através da superfície, favorecendo o diagnóstico e a compreensão de uma situação. Característica peculiar de uma radiografia é a sua apresentação visual de uma estrutura óssea (ou também muscular) já conhecida pelo leitor.

O termo Raio-X, com sentido análogo a painéis de informações, já é utilizado pelo Software Economatica (ECONOMATICA, 2008), que dispõe de uma base de dados e de recursos aplicados à análise de empresas participantes do mercado de capitais. A analogia para o setor público, até o alcance desta pesquisa, pode ser considerada inédita.

Na Figura 1 consta o painel proposto e na seção seguinte constam detalhamentos sobre as áreas do painel. A idéia que norteou a proposta foi a de ocupar uma única folha, com possibilidade de impressão em tamanho A4 $(21 \times 29,7 \mathrm{~cm})$, A3 $(29,7 x 42 \mathrm{~cm})$ ou em banner (painel em dimensões maiores para ser pendurado ou exposto). Deste modo, flexibiliza-se a forma de divulgação, que além de digital (na Internet e outros meios), também pode ser afixada em murais ou distribuída facilmente em outras formas de publicação, conforme a preferência dos usuários e as possibilidades institucionais.

Foi priorizada a utilização de cores e gráficos associados a tabelas, de forma a fornecer subsídios complementares para interpretação por parte dos leitores. Tais recursos e preferências são mais bem detalhados adiante, bem como as limitações inerentes à proposta. 


\section{Figura 1: Painel Raio-X da Universidade}

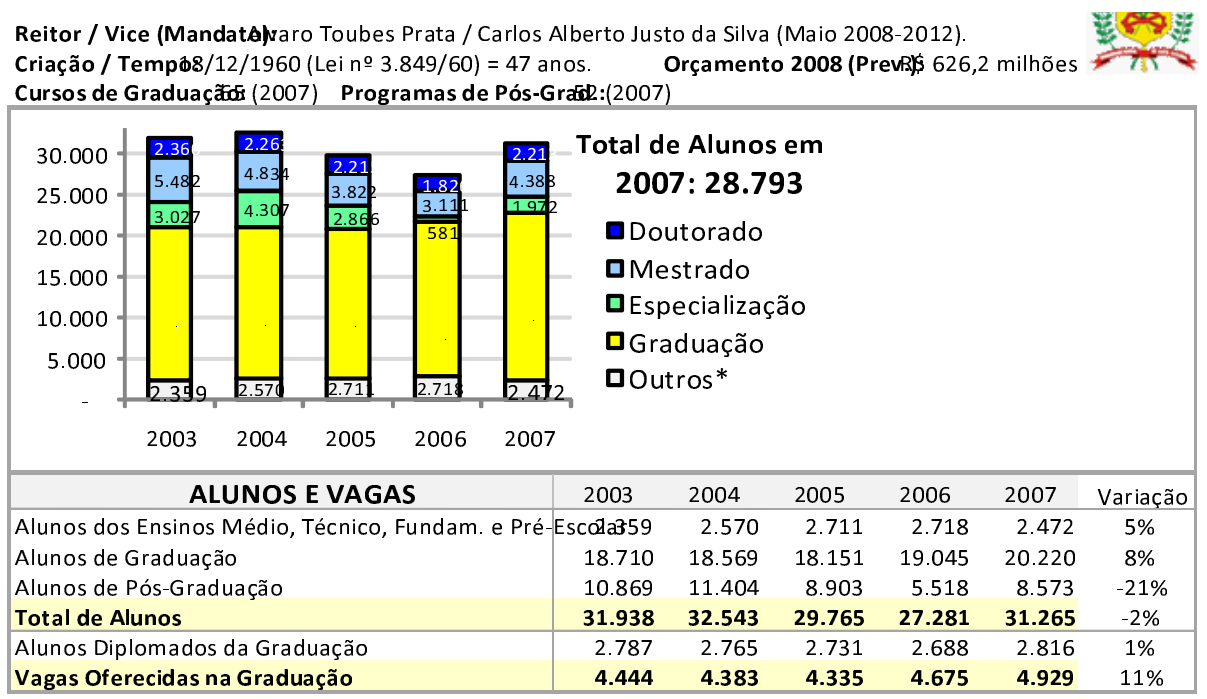

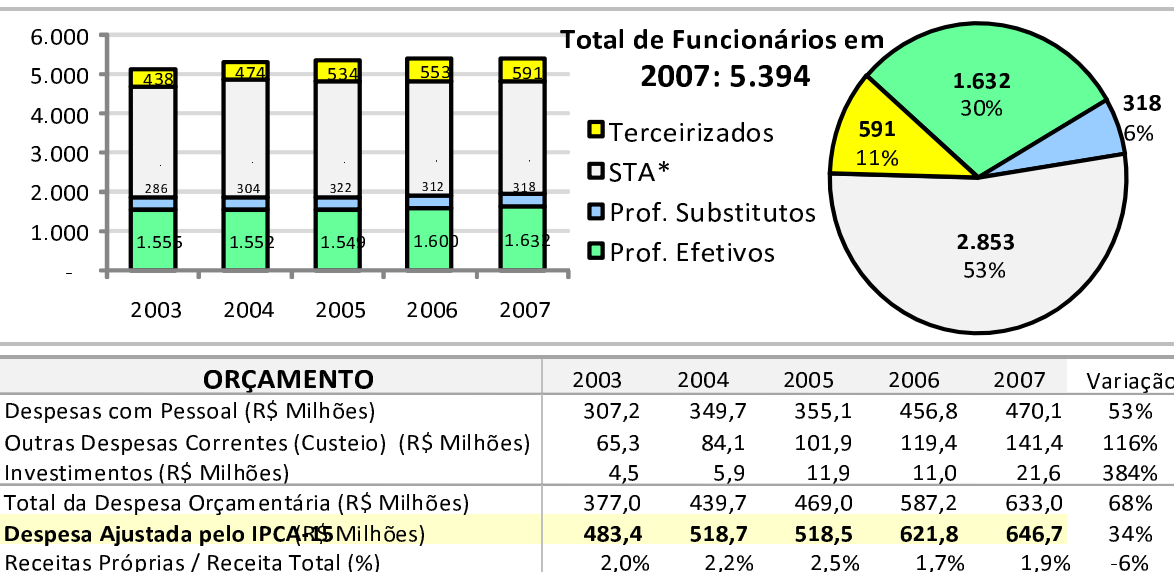

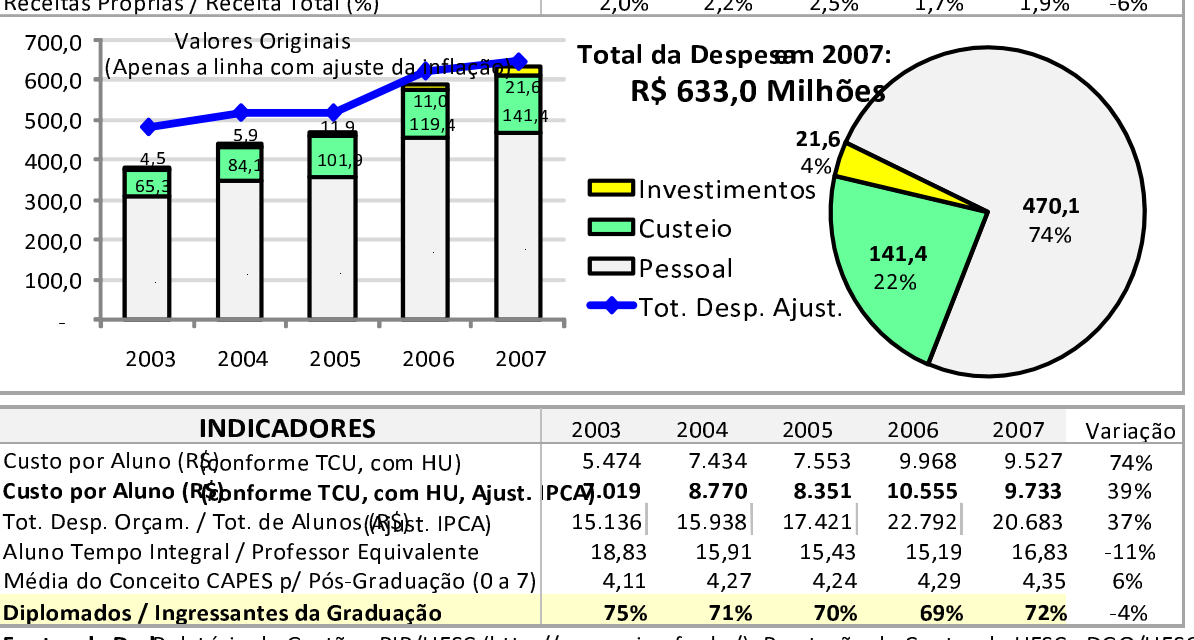

Fontes de Dadß̊øłatório de Gestão - PIP/UFSC (http://www.pip.ufsc.br/); Prestação de Contas da UFSC - DGO/UFSC

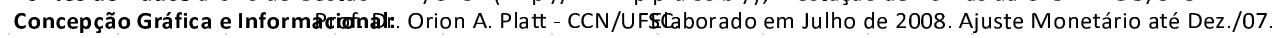

Fonte: Dados da pesquisa.

\subsection{Detalhamento das informações constantes na proposta}

Esta seção apresenta os principais grupos de informações componentes do painel proposto, sem a intenção de esgotar esclarecimentos metodológicos, que exigiriam espaço maior para detalhamento. 


\section{a) Grupo 1 - Cabeçalho:}

Este grupo identifica as seguintes informações: reitor e vice, acompanhados do período de mandato vigente; data e instrumento de criação da instituição, com o número de anos de existência; orçamento previsto para o ano em execução; número de cursos de graduação e de programas de pós-graduação.

\section{b) Grupo 2 -Alunos Atendidos:}

Este grupo identifica as seguintes informações: número de alunos atendidos, conforme as características do grau de estudo. Os alunos dos ensinos médio, técnico, fundamental e pré-escolar foram agrupados visando sintetizar a tabela e o gráfico. São fornecidos dois gráficos: uma série histórica de cinco anos, para percepção da evolução, e um perfil recente da composição global, no último ano, com percentuais.

Merece destaque a última coluna, que mostra a evolução no horizonte de tempo, com a variação percentual acumulada.

\section{c) Grupo 3 - Quadro de Trabalhadores:}

Este grupo evidencia informações sobre a força de trabalho que atua na Universidade, exclusivamente por meio de gráficos, visando sintetizar o volume de dados disponibilizados, por simples convenção do autor. São fornecidos dois gráficos: uma série histórica de cinco anos, para percepção da evolução, e um perfil da composição global, no último ano, com percentuais.

Merece destaque a evidenciação do quadro de pessoal terceirizado, que apesar de não contar com servidores públicos, representa pessoas atuando na realização de serviços na Instituição, incluindo pessoal de limpeza, vigilância e jardinagem, entre outros.

\section{d) Grupo 4 - Orçamento:}

Este grupo evidencia informações orçamentárias ligadas às despesas realizadas no horizonte de cinco anos, contando com tabela e gráficos. A série histórica é acompanhada de coluna que mostra a variação apresentada pelos valores. Merece destaque o ajuste inflacionário realizado nos valores referentes ao total da despesa orçamentária, que permite perceber uma variação com moeda em valores de poder aquisitivo da última data do ano de referência.

A despesa orçamentária está dividida em três grupos básicos, tipicamente adotados em função das normas de Contabilidade Pública aplicáveis, ou seja, a Lei $n^{\circ} 4.320 / 64$ e a Portaria STN/SOF $n^{\circ}$ 163/01, bem como atualizações posteriores.

São fornecidos dois gráficos: uma série histórica de cinco anos, para percepção da evolução, e um perfil da composição global, no último ano, com percen- 
tuais. O gráfico da série histórica apresenta uma linha com valores ajustados pela inflação, para permitir a comparação de evolução com as colunas não ajustadas, que carregam distorções inerentes à perda do poder aquisitivo da moeda.

O índice de preços utilizado foi o IPCA-15 (Índice Nacional de Preços ao Consumidor Amplo), do IBGE (2008), que é o índice de preços oficial do Governo Federal, utilizado inclusive para a definição e controle das metas de inflação da política monetária e fiscal do Brasil.

\section{e) Grupo 5 - Indicadores Diversos e Rodapé:}

Este grupo apresenta indicadores diversos, alguns apresentados prontos pela Instituição e outros calculados com vistas a fornecer outras informações entendidas como relevantes.

Os indicadores de Curso por Aluno apresentam tanto os dados originais apurados em atendimento à decisão do TCU, como os mesmos valores ajustados pela inflação, com vistas a minimizar distorções. A metodologia do indicador do TCU apresenta limitações conhecidas que não serão exploradas nesta pesquisa.

$\mathrm{O}$ indicador que apresenta da divisão da despesa orçamentária total, ajustada pela inflação, pelo número total de alunos atendidos pela instituição foi constituído especificamente para este painel. Deste modo, não há respaldo metodológico testado e legitimado para este indicador, pois não são feitos ajustes relativos aos diversos níveis de ensino abrangidos. Trata-se de uma conta simples de divisão entre variáveis.

Os três últimos indicadores são apurados em atendimento à decisão do TCU, que obriga todas as IFES a apurarem indicadores comuns. Em função de os detalhamentos metodológicos serem extensos, eles estão sendo omitidos nesta pesquisa.

Por fim, consta o rodapé, no qual são indicadas as fontes básicas dos dados utilizados. Deve-se notar que apesar de constarem apenas duas fontes, principalmente o Relatório de Gestão, tal documento consolida muitos outros dados institucionais fornecidos por setores diversos que controlam os dados.

\subsection{Limitações inerentes e possibilidades de customização informacional}

O painel constitui uma proposta sugerida quanto à forma de evidenciação de conteúdos entendidos como relevantes, prezando pela síntese e economia no uso de espaço, com vistas a não sobrecarregar o leitor, além do cuidado estético e do uso de recursos visuais. Trata-se de uma idéia subjetiva e baseada em pressupostos, pois determinado volume de informações que sobrecarrega um grupo de usuários pode ser insuficiente para outros.

Tendo em vista a multidimensionalidade de aspectos e a diversidade de 
áreas de atuação das universidades, que expressam suas peculiaridades, considera-se impossível tratar de todas as informações existentes e/ou desejadas pelos usuários. Todavia, muitas vezes os próprios usuários não têm nem mesmo idéia do que desejam exatamente saber. Este pressuposto enfatiza a importância de um auxílio técnico por parte de profissionais especializados, que tentam "enxergar com os olhos dos outros".

Deste modo, não há a pretensão de apresentar uma versão definitiva e, muito menos, impor verdades absolutas. Por este motivo, a proposta apresenta-se como uma estrutura aberta para adaptações, ou seja, uma customização informacional aos interesses dos usuários em potencial.

\section{Considerações Finais}

Considera-se atingido o objetivo do artigo, de apresentar a proposta de um painel de informações institucionais básicas de universidades brasileiras, a partir de uma concepção sintética e ilustrada. O Painel intitulado "Raio-X" foi aplicado na Universidade Federal de Santa Catarina (UFSC), conforme demonstrado e detalhado no capítulo de resultados deste artigo.

A revisão de literatura forneceu subsídios para entender o princípio constitucional da publicidade e o princípio legal da transparência, que revestem as contas e demais informações sobre as universidades públicas. Deste modo, foi enfatizada a exigência de prestação de contas e de serem fornecidas informações à população em geral sobre tais instituições. Ainda na revisão de literatura, foram apresentados os diversos usuários externos das contas públicas das universidades, acompanhados de uma síntese de seus interesses presumíveis.

No capítulo de resultados, foi apresentada a instituição utilizada no estudo e foram identificadas as principais publicações que contém informações sobre a Instituição. Com base nos pressupostos assumidos e nos princípios norteadores, foi apresentada a proposta de um painel de uma página. Foi priorizada a utilização de cores e gráficos associados a tabelas, de forma a fornecer subsídios complementares para interpretação por parte dos leitores. A série histórica de cinco anos ampliou a percepção de evolução dos dados, especialmente quando associada ao ajuste monetário de valores.

Destaca-se que o painel constitui uma proposta sugerida quanto à forma de evidenciação de conteúdos entendidos como relevantes, enfatizando a síntese e primando pela economia no uso do espaço, com vistas a favorecer o tempo despedido pelo leitor, além do cuidado estético e do uso de recursos visuais.

As limitações da proposta derivam da multidimensionalidade de aspectos e da diversidade de áreas de atuação das universidades, que expressam suas peculiaridades. Deste modo, considera-se impossível tratar de todas as informações existentes e/ou desejadas pelos usuários. Assim, não houve a pretensão de apresentar uma versão definitiva e, muito menos, impor verdades absolutas. Por este 
motivo, a proposta foi apresentada como uma estrutura aberta para adaptações, ou seja, uma customização informacional aos interesses dos usuários.

Para pesquisas futuras, recomenda-se que seja aplicado o painel proposto em outras Instituições Federais de Ensino Superior, tendo em vista as muitas semelhanças institucionais destas entidades da administração pública federal do Brasil. No que tange à Instituição estudada (UFSC), recomenda-se a divulgação institucional à comunidade acadêmica e a outros usuários interessados, em meios como murais, jornais, Internet e eventos. Pesquisas junto aos usuários poderão revelar outras informações consideradas relevantes, com vistas ao aprimoramento contínuo da proposta.

\section{Referências}

BRASIL. Constituição (1988). Constituição da República Federativa do Brasil, promulgada em 5 de outubro de 1988.

Lei $\mathbf{n}^{\mathbf{0}}$ 3.849, de 18 de dezembro de 1960. Federaliza a Universidade do Rio Grande do Norte, cria a Universidade de Santa Catarina e dá outras providências.

Lei $\mathbf{n}^{\mathbf{0}} \mathbf{4 . 3 2 0}$, de 17 de março de 1964. Estatui normas gerais de direito financeiro para elaboração e controle dos orçamentos e balanços da União, dos estados, dos municípios e do Distrito Federal.

. Lei n⿳0 9.755, de 16 de dezembro de 1998. Dispõe sobre a criação de "homepage" na "Internet", pelo Tribunal de Contas da União, para divulgação dos dados e informações que especifica, e dá outras providências.

. Lei Complementar $\mathbf{n}^{\mathbf{0}}$ 101, de 4 de maio de 2001 (Lei de Responsabilidade Fiscal). Estabelece normas de finanças públicas voltadas para a responsabilidade na gestão fiscal e dá outras providências.

CGU - Controladoria-Geral da União. Presidência da República. Portal da Transparência. Disponível em: $<\mathrm{http}$ :/www.portaltransparencia.gov.br $>$. Acesso em: 11 jul. 2008.

. Portaria no 262, de 30 de agosto de 2005. A forma de divulgação dos relatórios e dos certificados de auditoria, com pareceres do órgão de controle interno, e dos pronunciamentos dos Ministros de Estado supervisores das áreas ou das autoridades de nível hierárquico equivalente, contidos nos processos de contas anuais, submete-se ao disposto nesta Portaria. 
CRUZ, Flávio da et al. Lei de Responsabilidade Fiscal comentada: Lei Complementar no 101, de 4 de maio de 2000. 2. ed. São Paulo: Atlas, 2001. 346 p.

ECONOMATICA. Software com base de dados para análise de empresas Raio-X. Disponível em: <http://www.economatica.com/pt/>. Acesso em 28 ago. 2008.

GRUPO DE CONTATO - Tribunal de Contas da União (TCU); Secretaria da Educação Superior (SESu/MEC); e Secretaria Federal de Controle Interno (SFC). Manual de Orientação para Cálculo dos Indicadores de Gestão: Decisão TCU no 408/2002-Plenário. Versão revisada em janeiro/2006. 8p.

IBGE - Instituto Brasileiro de Geografia e Estatística. IPCA-15: Índice Nacional de Preços ao Consumidor Amplo-15. Disponível em: <http://www.ibge.gov.br/ home/estatistica/indicadores/precos/ipca15/defaultipca15.shtm>. Acesso em: 28 ago. 2008.

Pesquisa sobre acesso à Internet da população brasileira. Disponível em: <http://www.ibge.gov.br/>. . Acesso em: 28 ago. 2007.

STN e SOF - Secretaria do Tesouro Nacional (STN), do Ministério da Fazenda (MF); e Secretaria do Orçamento Federal (SOF), do Ministério do Planejamento, orçamento e Gestão (MPOG). Portaria Interministerial n⿳ 163, de 4 de maio de 2001. Dispõe sobre normas gerais de consolidação das Contas Públicas no âmbito da União, Estados, Distrito Federal e Municípios, e dá outras providências.

TCU - Tribunal de Contas da União. Homepage Contas Públicas. Disponível em: <http://www.contaspublicas.gov.br>. Acesso em: 11 jul. 2008.

Decisão TCU no 408/2002 - Plenário. Auditoria Operacional. Relatório consolidado. Universidades federais. UNB. FUAM. UFGO. UFPE. UFRJ. UFRS. Elaboração de diagnóstico na área de ensino público superior. Levantamento de indicadores de desempenho. Determinação. Ciência ao Congresso Nacional e órgãos de supervisão e controle. Juntada às respectivas contas. 2002.

UFSC - Universidade Federal de Santa Catarina. AUDIN - Unidade de Auditoria Interna. Reitoria da UFSC. Relatórios de Atividades. Disponível em: <http:// www.audin.ufsc.br/>. Acesso em: 11 jul. 2008.

29 ago. 2008.

. Missão da UFSC. Disponível em: $<$ http://www.ufsc.br/>. Acesso em: . DCF - Departamento de Contabilidade e Finanças. Balanços Públicos 
da UFSC. Disponível em: <http://www.reitoria.ufsc.br/dcf>. Acesso em: 11 jul. 2006.

. DGO - Departamento de Gestão Orçamentária. Orçamentos da UFSC. Disponível em: <http://www.reitoria.ufsc.br/dgo>. Acesso em: 11 jul. 2008.

. DIE - Departamento de Integração e Estatística. Informações sobre o setor. Disponível em: <http://www.die.ufsc.br/>. Acesso em: 11 jul. 2008.

. Relatório de Gestão 2007. Disponível em: $<$ http://www.die.ufsc.br/ arquivos/RELATORIO_GESTAO_2007.pdf >. Acesso em: 11 jul. 2008. 
